\title{
GEOGRAFIA E PESCA: APORTES PARA UM M ODELO DE GESTÃO
}

\author{
Eduardo Schiavone Cardoso*
}

\begin{abstract}
Resumo: 0 presente trabalho fornece elementos para o estudo geográfico das pescarias e para a análise de um modelo de gestão desse setor produtivo. Analisa ainda a contribuição de pescadores artesanaina formação de um novo enfoque para o desenvolvimento da atividade pesqueira.
\end{abstract}

Palavras- chave: Pesca; Pescadores; Pesca artesanal; Território.

\section{Introdução}

A questão pesqueira tem sempre permeado os estudos geográficos. Ora como objeto central, ora como pano de fundo no estudo de comunidades e áreas litorâneas ou ribeirinhas, o estudo geográfico da pesca forneceu importantes análises desse setor produtivo.

Trabalhos já clássicos como os de BERNARDES \& BERNARDES (1950), BERNARDES (1959) e LAGO (1961) apontam para as relações entre a atividade pesqueira e a natureza, o papel das comunidades de pescadores na estruturação das paisagens litorâneas e mesmo aportes tecnológicos fornecidos por imigrantes para a pesca.

A esses, somam-se os estudos sobre o litoral, em especial o litoral norte paulista, realizados em meados do século $X X$, que descrevem os processos de ocupação dessa região e a presença das comunidades de pescadores caiçaras. Dentre eles, destacam-se os trabalhos de CARVALHO (1944) e FRANÇA (1954) .

Ainda sobre o litoral norte paulista, porém em anos mais recentes, teses e dissertações produzidas no âmbito do Departamento de Geografia da FFLCH-USP, apontam novas problemáticas ligadas à atividade pesqueira e aos processos dinâmicos de urbanização e avanço turístico nesse trecho do litoral. Como exemplo, podemos citar NOFFS (1988), CALVENTE (1993), entre outros.

Evidentemente, esta pequena introdução não tem por objetivo resgatar toda a produção geográfica sobre a atividade pesqueira. Cabe aqui chamar a atenção para a necessidade de se analisar a atividade pesqueira em seu momento atual, como um setor produtivo que comporta questões eminentemente geográficas, tais como a da relação sociedade - natureza e a da gestão do território.

\section{Antecedentes}

0 histórico do desenvolvimento do setor pesqueiro no Brasil pode ser encontrado em diversos autores que trabalharam com a questão (SILVA, 1972; DIEGUES, 1983; MELLO, 1985; CARDOSO, 1996). Nesta análise, é proposto um 
corte que sinaliza três processos alavancados pelo Estado no decorrer do século XX, que levaram à configuração de um modelo de gestão das pescarias, cuja crise é evidente e a superação ainda não se encontra totalmente delineada.

0 primeiro, estudado por SILVA (1991), é 0 da formação do estado nacional e do estabelecimento da marinha de guerra brasileira. Como estratégia de consolidação desse organismo das forças armadas, a marinha atrelou a si os pescadores brasileiros, através da criação do sistema organizativo da categoria: colônias, federações e confederação nacional de pescadores.

O segundo processo é a "modernização" da pesca, promovida pela SUDEPE (Superintendência de Desenvolvimento da Pesca), a partir da década de 1960. Essa política destinou recursos para a criação e reprodução de uma estrutura industrial para 0 setor pesqueiro, através de incentivos fiscais para a compra de barcos e equipamentos e para a implantação de unidades de beneficiamento do pescado, entre outras ações de fortalecimento de uma pesca "moderna".

Finalmente, o terceiro processo refere-se ao que BRETON \& ESTRADA (1989) chamam de consolidação dos nacionalismos marinhos. Decretado unilateralmente durante os anos 70, o mar territorial de 200 milhas teve vida curta. Os acordos para a entrada em vigor das resoluções da CONVEM AR de 1982, a respeito do Mar Territorial e das Zonas Econômicas Exclusivas, trazem desafios contemporâneos para 0 ordenamento da atividade pesqueira em mar alto.

Eleger esses três processos como os antecedentes do que se pode chamar de uma "crise de um modelo de gestão das pescarias" remete a uma observação estrutural da atividade pesqueira. Para Breton e Estrada:

[...] en lugar de haber logrado absorber el conjunto de los factores de la producción pesquera, el capitalismo hasta ahora ha influido sobre todo en el plano de la tecnologia; ha tenido que conformarse con un control y con una planificación parciales a nivel de los otros dos elementos constitutivos de las fuerzas productivas, es decir los recursos haliéuticos como objeto de trabajo y los productores como fuerza de trabajo (BRETON \& ESTRADA,1989).

Ao estabelecer as colônias de pescadores e o restante do sistema representativo da categoria, os interesses hegemônicos que controlavam o estado brasileiro procuraram aumentar o controle sobre a força de trabalho na pesca - os pescadores. Com o fomento das indústrias de pesca a partir da SUDEPE, o Estado logrou o avanço tecnológico e com a delimitação das 200 milhas pretendeu-se controlar através do território 0 objeto de trabalho.

Esses três processos podem ser interpretados como possuidores de uma mesma lógica, uma mesma racionalidade, uma mesma ideologia: a da pesca racional, moderna, baseada na tecnologia, com pescadores comportados, valorizando a pátria. Discurso presente até os dias de hoje, à mercê dos escândalos, desperdícios, depredações e limites naturais de expansão desse modelo, que a história das últimas três décadas do setor pesqueiro revelou abertamente.

Autores como DIEGUES (1983), MELLO (1985), LOUREIRO (1985), entre outros, já analisaram esse projeto político, que tinha como premissa a transformação do setor pesqueiro de pesca artesanal em pesca moderna, tendo por base a industrialização. Apenas como exemplo, os incentivos fiscais de 134 projetos aprovados pela SUDEPE em 1968, 69 e 70 totalizavam CR $\$ 1.644 .379 .113,00$, sendo que a produção pesqueira desses três anos atingiu um valor total de CR\$ 1.222.915.000,00, ou seja, o valor da produção da pesca ficou em torno de $75 \%$ do valor aprovado para as empresas sob a forma de incentivos fiscais, em um período de três anos (JORNAL DA PESCA, 1971, IBGE, 1971).

De fato 0 setor transformou-se. 0 crescimento verificado na produção pesqueira brasileira desse período teve por base um investimento maciço nas frotas e plantas industriais de pescado, com a finalidade primeira de gerar produtos para a exportação. 0 salto de cerca de 300.000 para 900.000 toneladas de pescado em pouco mais de duas décadas demonstrava uma possibilidade de incremento de produção, que mostrou seus limites na década de 1990. Aliado a isso, mostrou uma outra faceta bem apontada por DIEGUES (1983):

[ ...] a dinâmica do capital leva não somente à exploração dos trabalhadores do mar, mas também ao desrespeito das leis que regulam o metabolismo da natureza.

A sobrepesca de algumas espécies, a pesca predatória de outras tantas e a destruição de ecossistemas de alta produtividade são algumas das conseqüências que acompanharam o desenrolar do projeto de modernização do 
setor pesqueiro, contribuindo para a redução do pescado situado junto à costa. Ainda junto à costa, nas áreas de atuação da pesca artesanal, verificou-se um aumento da disputa pelo pescado (LOUREIRO, 1985). Parte da frota industrial atuando com técnicas predatórias para as baixas profundidades próximas à costa acarretaram a diminuição da oferta de pescado para os pescadores artesanais, cujos meios de produção não Ihes possibilitam um deslocamento mais amplo, acirrando disputas pela apropriação desses espaços e do pescado neles contido.

Esse modelo de desenvolvimento do setor vem sendo questionado pelos pequenos produtores pesqueiros. Mais que questionado, tal modelo parece ter chegado a seu limite de expansão. Teria chegado a uma crise?

\section{A crise de um modelo}

Hoje, dez anos após a extinção da SUDEPE, cujas atribuições passaram ao IBAMA, o setor pesqueiro se reproduz sem uma política clara estabelecida pelo governo ${ }^{1}$. Mesmo as estatísticas de pesca, que eram precariamente produzidas, deixaram de ser sistematicamente produzidas e divulgadas. Estima-se que a produção pesqueira decresceu para a faixa de 700.000 toneladas anuais (DIAS NETO, 1996). Nos portos 0 abandono das frotas é visível. Barcos de seis tripulantes são operados por dois ou três pescadores como forma de obter uma rentabilidade mínima. A abertura do mercado ampliou a oferta de pescado a baixo preço, em especial a proveniente dos países do Mercosul, causando 0 fechamento de indústrias de beneficiamento que, já em sua origem, apresentavam problemas de capacidade ociosa instalada. 0 peixe está entre as proteínas animais mais caras. Estimativas globais para o potencial pesqueiro brasileiro situavam-no na faixa de 1.400 .000 a 1.700 .000 toneladas capturáveis de forma sustentável (DIEGUES et al., 1992). Nunca atingimos essas marcas, e as principais espécies comerciais já atingem estágios de sobrepesca.

Pode-se falar em uma crise do setor da pesca industrial, ou mais precisamente em uma crise de um modelo de desenvolvimento da pesca baseado no uso intensivo de capital e tecnologia.

Em artigo de 1972, o então contra-almirante Paulo de Castro Moreira da Silva já anunciava essa crise. Analisando a estrutura de produção e mercado do pescado brasileiro, profetizava:
A pesca brasileira, tão subsidiada, faltou à sua missão mais essencial: alimentar as populações mais pobres do Brasil. Arriscou tudo em uma única cartada: o camarão exportado. Haja camarão a exportar, na abundância que requer, para salvar-se o nosso colossal investimento. [...] Mas o índio defumando, 0 índio fazendo farinha de peixe para alimentação humana, usando suas jangadas e canoas (mas aprendendo bem rápido a usar o anzol de ferro e a grande rede dos franceses), finalmente tinha mais razão(SILVA, 1972).

\section{A pesca artesanal}

Quando nos referimos à crise de um modelo de gestão das pescarias baseado no uso intensivo de capital e tecnologia, propositadamente não nos referimos à outra face da moeda, a produção dos pescadores artesanais, pescadores simples.

Como pesca artesanal entendemos a pesca realizada dentro dos moldes da pequena produção mercantil, que comporta ainda a produção de pescadores-agricultores, segundo o conceito de DIEGUES $(1983,1988)$. Trata-se de uma pesca realizada com tecnologias de baixo poder predatório, levada a cabo por produtores autônomos, empregando força de trabalho familiar ou do grupo de vizinhança.

Em realidade, a questão conceitual sobre pesca artesanal é bem mais ampla. No momento é importante apreender que são os pequenos produtores pesqueiros que se têm levantado como sujeitos sociais, novos personagens que entram em cena, um setor da força produtiva que politiza seu movimento (SADER, 1995, SILVA, 1998). A identidade é encontrada na oposição a uma outra coisa, no conflito e no embate político, em especial nos conflitos entre estruturas produtivas com diferentes graus de incorporação tecnológica e de capital.

Sujeitos alijados das políticas públicas da SUDEPE, OS pequenos pescadores presenciaram suas áreas de pesca serem objeto de avanço da frota pesqueira de armadores e empresas acirrando a competição pelo pescado, viram-se subordinados por um mercado que, dominado por atravessadores de pescado, subtrai seus rendimentos e tiveram seus espaços de vida reduzidos pelo avanço da especulação imobiliária pelo litoral, apenas para citar alguns dos processos que se exponencializaram ao longo das últimas três décadas. 
Aqui cabe uma constatação. Diante de todos esses processos, a pesca artesanal sobreviveu e, mais que isso, se reproduz. Nas últimas estatísticas oficiais representava cerca de $50 \%$ da produção brasileira e era responsável por cerca de $75 \%$ do valor gerado na pesca (IBGE,1990, 1991). Não se trata de retomar a história de sua importância. MARTINS (1986) nos indica que é uma produção de dentro do modo capitalista de produzir. Alguns autores inclusive apontam para a recampenização das pescarias (BRETON \& ESTRADA, 1989). Trata-se aqui de resgatar uma outra dimensão: a emergência de um novo personagem social - os pescadores artesanais enquanto um movimento gerido no pós 64 e que ganha visibilidade em meados da década de 80 .

Como sujeitos sociais, os pescadores estiveram presentes em momentos cruciais da história brasileira. Conforme já nos indicou SILVA (1988), pescadores atuaram na independência, na abolição da escravatura, na Revolta dos Cabanos e em outros momentos da vida nacional. 0 que é um dado novo é a visibilidade que ganharam como sujeitos sociais, como agentes principais de um modelo de gestão das pescarias diferenciado e como sujeitos políticos.

\section{Pescadores em movimento}

Em agosto de 1990 e em outubro de 1991, em Juazeiro (BA) e Olinda (PE) respectivamente, pescadores artesanais organizados em torno do Monape - Movimento Nacional de Pescadores organizaram encontros em que se discutiu a questão ambiental (M ONAPE, 1991; DIEGUES, 1992). Foram feitas denúncias de degradação dos ecossistemas litorâneos e de águas interiores, levada a cabo pela poluição ambiental e industrial, especulação imobiliária, desmatamentos, queimadas, despejos de vinhoto e mercúrio, aterros de mangues e lagoas, assoreamento de rios e derramamentos de petróleo.

Como a qualidade dos ambientes aquáticos está estritamente ligada à produtividade das pescarias e, conseqüentemente, à reprodução das sociedades de pescadores, estes têm tomado a linha de frente nas denúncias e ações contra a degradação. Ainda nos anos 60 , e durante os 70 e início dos 80, antes do boom ecológico, pescadores pernambucanos organizaram manifestações em defesa dos rios e estuários daquele estado, contra a poluição oriunda das indústrias e engenhos (SILVA, 1989).

A criação de parques e reservas naturais em áreas de morada e trabalho de pescadores tem também sido alvo de denúncias por parte destes, uma vez que as restrições de uso acabam comprometendo a sua reprodução. Essas denúncias são recorrentes em encontros entre pescadores, agricultores, técnicos e acadêmicos, organizados pelo Projeto Cultural São Sebastião Tem alma, em conjunto com outras entidades, realizados entre 1990 e 1994 em São Sebastião, São Paulo, (PCSSTA, 1990, 1993; PCSSTA/PPCAUB, 1990; PCSSTA/CEM AR, 1992; PCSSTA/NUPAUB-USP/FSSI, 1994).

A preservação da natureza também foi objeto de discussão de um encontro entre pescadores realizado em Óbidos (PA) em 1984, cujas conclusões apontam para a preservação das nascentes, capinzais e matas ciliares, e para a proibição da pesca com artes predatórias, da captura de peixes jovens, filhotes e ovados e da pesca de geleiras nos lagos de arrimo das comunidades (FURTADO, 1993).

Por ocasião da ECO-92, durante o Fórum Global que reuniu ONGs de vários países, foi elaborado um "Tratado sobre a pesca", situando a importância da pesca artesanal na conservação dos recursos e na proteção dos ambientes marinhos, costeiros e de águas interiores (FÓRUM de ONGs, 1992).

Os documentos expostos não só apontam para os conflitos entre a atividade pesqueira e os demais usos dos espaços litorâneo, marinho e flúvio - lacustre, como delineiam a importância do que se convencionou tratar de pesca artesanal, na preservação dos recursos naturais. Essa importância baseia-se na adoção de técnicas de captura de maior seletividade e de menor escala de predação, que podem ser consideradas menos impactantes para 0 ambiente explorado. Pode-se estabelecer uma outra relação, à medida que as sociedades pesqueiras, fixas ao longo do litoral e demais corpos d'água, teriam entre suas preocupações a continuidade e reprodução das pescarias, advindo uma maior necessidade de preservação dos recursos pesqueiros.

Não é apenas em relação à questão ambiental que emergem propostas no interior da categoria dos pequenos produtores pesqueiros. Uma descrição rápida das observações efetuadas em campo aponta para propostas relativas ao estabelecimento de uma política pesqueira mais adequada, com linhas de crédito compatíveis com a atividade, política previdenciária, e propostas para a saúde e a educação em localidades de pescadores. Para além das propostas, pescadores realizam ações em suas vilas, praias, povoados e cidades.

A questão da organização da categoria de pescadores merece destaque nesse rol de propostas. Com seu sistema organizativo (colônias, federações estaduais e confederação 
nacional) imposto de "cima para baixo", grupos de pescadores passaram a questionar seus organismos de representação. Perceberam que algumas de suas propostas passavam ao largo de seus supostos órgãos de representação, dominados por políticos, comerciantes e oficiais da marinha. Como mudar tal situação? 0 caminho foi a conquista desses organismos. $\mathrm{Na}$ Constituição de 1988, o movimento constituinte da pesca logrou equiparar as colônias de pescadores aos sindicatos, rompendo uma larga história de intervenção no processo de organização dos pescadores.

Do papel à realidade o caminho é mais tortuoso. Enquanto pescadores de algumas localidades conquistaram suas colônias e federações, democratizando os processos eletivos e gerindo-as de acordo com interesses legítimos da categoria, em outras situações predominam o poder do atraso, com interventores nomeados administrando esses organismos, e interesses alheios à categoria indicando seus representantes legais.

A mudança do papel e da ação das colônias, federações e confederação nacional de pescadores e os embates daí decorrentes apontam para um outro nível de propostas do movimento de pescadores, que passam a ter voz própria.

Como subsídio para a análise deste rol de propostas e ações do movimento de pescadores, é interessante refletir sobre as palavras de MARTINS (1989):

Há uma diversificação interna das classes subalternas cujo desconhecimento empobrece a compreensão de suas lutas e de suas possibilidades históricas, porque omite os seus dilemas e suas debilidades. Um discurso que unifique retoricamente as classes subalternas não produz a unidade e a força reais dessas classes e grupos sociais. Ao contrário, mistifica-as e empobrece a interpretação de sua realidade.

Nesse sentido, apreender as práticas formais e informais dos grupos de pescadores, suas ações legais ou à parte da legalidade, individuais ou coletivas, permitirá vislumbrar um modelo incipiente para a gestão das pescarias. Não se constitui ainda em uma bandeira de luta unificada, mas aponta para necessidades e anseios presentes no mundo da pesca e que comportam uma visão diferenciada para 0 setor, que luta por seu espaço político. Algumas delas trazem forte componente territorial. É o que veremos a seguir.

\section{Território e pescarias}

0 território é tratado aqui por seu valor de uso para 0 grupo social ${ }^{2}$. Delimitado formal ou informalmente, garante a reprodução dos pescadores e transforma-se em instrumento de gestão das pescarias. Passa a compor o rol de propostas dos pescadores e representa uma outra relação de apropriação do ambiente marinho.

0 conceito de território pode ser estendido ao mundo das águas, apropriado pelos pescadores em seu trabalho. MALDONADO (1993), estudando pescadores marítimos paraibanos, observa que:

No mar, os territórios são mais do que espaços delimitados. São lugares conhecidos, nomeados, usados e defendidos. A familiaridade de cada grupo de pescadores com uma dessas áreas marítimas, cria territórios que são incorporados à sua tradição [...].

MARQUES (1995), em estudo sobre etnoecologia no baixo São Francisco, observa a noção de territorialidade entre brejeiros de Marituba (AL) expressa pela posse, delimitação, defesa e marcação das áreas. Marcação que "[...] é uma instância em que se constrói, se expressa e se atualiza a territorialidade dos pescadores [...]"(MALDONADO, 1993).

Formas de territorialidade marinha ou fluvial relacionam-se intimamente com os sistemas de pesca. Dada a mobilidade do aparelho de captura, o espaço de pesca a ser percorrido é de uma extensão maior ou menor. A traineira desloca-se por entre áreas de centenas de quilômetros quadrados na costa sul e sudeste brasileira, em busca dos cardumes de sardinha. No extremo oposto, os cercos fixos ou flutuantes são armadilhas pontuais que, ao obstruir a passagem do cardume, o dirige para dentro da armadilha. Quem se move é o pescado e não o pescador.

A dicotomia pesca/despesca, observada por MALDONADO (1986) na Paraíba, por CUNHA (1987) em Santa Catarina e por nós no litoral paulista é reveladora dessa forma de lidar com o território marinho na pesca. Quem pesca é a rede de espera, o cerco flutuante ou fixo, cabendo ao pescador 0 trabalho da despesca. 0 instrumento possui a ação e o ponto de pesca, importância na espera do pescado.

$\mathrm{Na}$ pesca, e não na despesca, é o pescador que se desloca, que sai em busca do pescado, no arrasto, no anzol,

(2) Segundo Moraes, o conceito de território é oriundo dos estudos de Botânica e Zoologia do final do século XVIII e foi sendo incorporado às análises geográficas. Com a chamada Geografia Crítica, o conceito de território foi retrabalhado a partir da proposição marxista de que o que define um território é 0 uso que se faz de uma determinada porção do globo, a partir de uma relação de apropriação, qualificada pelo trabalho social ( M ORAES, 1984). 
na rede de cercar, na rede de caceio. São pescarias mais ativas, ainda que o conhecimento dos locais e a seleção dos pontos de pesca orientem o deslocamento do pescador.

Formas de gestão das pescarias ligadas diretamente aos pontos de pesca podem ser encontradas na pesca fluvial, lacustre, lagunar ou marinha.

Nos rios e lagos, a ceva do pescado representa uma forma de territorialidade pesqueira. Escolhido um determinado ponto, o pescador aporta uma certa quantidade de alimentos para atrair 0 pescado e ali lançar posteriormente suas redes e anzóis. No rio São Francisco, 0 lanço é uma unidade territorial de pesca. Em acampamentos às margens do rio, ou em áreas próximas às moradias ribeirinhas, grupos de pescadores limpam um trecho do fundo do rio para onde será lançada a rede, impedindo que, por exemplo, galhadas de árvores submersas obstruam o correr do lanço de rede.

Em ecossistemas lagunares e estuarinos, de sul a norte do país, uma diversidade de armadilhas fixas de pesca representam uma apropriação do espaço aquático através de uma forma territorial. Os aviõezinhos do sul do país, o cerco fixo da região estuarino lagunar de lguape - Paranaguá, as caiçaras das lagoas alagoanas e os currais de pesca do norte e nordeste do país correspondem a apetrechos de pesca cujo ponto de instalação representa uma apropriação territorial, de forma individual ou do grupo, de um trecho de água. São sinais da territorialidade no mundo pesqueiro, reforçada pela necessidade, em alguns casos, de requerimentos formais de instalação junto a organismos como a Capitania dos Portos, Ibama ou órgãos licenciadores estaduais.

Saindo do universo de ecossistemas relativamente fechados e partindo para 0 ambiente de mar aberto, encontramos também formas de territorialidade na pesca. $\mathrm{Na}$ Ilha Grande (RJ), depoimentos relatam a existência de sistemas de pesca que comportavam rodízios de áreas de pesca. Por três pontos de pesca, delimitados a partir dos esporões rochosos da ilha e suas enseadas adjacentes, turmas de pescadores revezavam-se diariamente. 0 pescado observado a partir de determinado esporão, e que adentrava a enseada, era capturado preferencialmente pela turma de pesca daquele ponto, naquele dia. 0 revezamento se justificava pela direção preferencial de deslocamento dos cardumes, fazendo que uma área tivesse maior produtividade do que outra.

0 pesqueiro, o cabeço, 0 valão e outras áreas marinhas diferenciadas por serem refúgios naturais de pescado em mar aberto, são territórios apropriados pelos pescadores a partir de seu conhecimento e sua práxis.

Chegar ao pesqueiro requer o domínio do território marinho e de uma série de elementos naturais que 0 compõem, tais como o relevo submarino, os ventos, as marés, as formas de terra que representam os referenciais de localização, as profundidades da coluna d'água e a cor da água. E a apropriação desse território pelo pescador é um processo de mediação com a natureza.

No caso da atividade pesqueira, em especial na pesca marítima, os pescadores produzem seu território em um meio aparentemente indiviso e de grande mobilidade e a pesca pressupõe uma interação contínua com a natureza. $\mathrm{Na}$ apropriação desse meio constroem-se os territórios da pesca. Essa apropriação, é mediada pelo

[...] nível tecnológico do instrumental pesqueiro e sobretudo pelo conhecimento do meio marítimo que cada grupo constrói e desenvolve na sua atuação frente à natureza [...] (MALDONADO, 1988 ).

\section{Propostas territoriais de gestão das pescarias}

"A criação de áreas exclusivas para a pesca artesanal como forma de garantir a reprodução das espécies e reposição dos estoques pesqueiros", proposta no 5 - Encontro de Pescadores do MONAPE, realizado em Olinda, 1991, abrange uma série de reivindicações particulares. Representa a delimitação de um território para pequenos pescadores, uma reivindicação que tem por base 0 conflito entre formas distintas de produção pesqueira.

Em workshop realizado em 1991, em Belém, promovido pela Associação Brasileira de Antropologia, foram elaboradas propostas para a proibição do arrasto de camarão na foz do Amazonas e da piramutaba no estuário do mesmo rio, na tentativa de fixar marcos territoriais para a atuação das frotas empresariais..

No encontro de Óbidos, já citado, é reivindicada

[...]uma demarcação de áreas pesqueiras por parte da SUDEPE, onde a pesca artesanal possa ter seu livre curso ...com vistas a se criar ou estimular a instalação de reservas permanentes e/ou sazonais como meta de preservação dos recursos da natureza e reprodução social da população envolvida no processo (FURTAD01993).

Essa proposta é muito próxima da surgida sete anos 
depois em Olinda e também da presente na Conferência dos Trabalhadores da Pesca, realizada em Roma em 1984, por iniciativa da FAO, em cujas recomendações estava contemplado: "Reservar e proteger para a pesca artesanal as águas litorâneas e quaisquer zonas que dêem acesso a elas".

Essa proposição também está presente nas propostas dos encontros realizados em São Sebastião, já citados. Entretanto, nesses encontros, áreas mais específicas são objeto de reivindicação para a pesca artesanal, como por exemplo a proteção de enseadas e baías contra a pesca de arrastos, traineiras e parelhas, a proteção do entorno das ilhas habitadas contra 0 arrasto e a pesca submarina; 0 balizamento marinho de um trecho de ilhas e enseadas contra a pesca predatória, e a cobrança para que a legislação, que delimita uma distância mínima para as operações de arrasto, seja cumprida.

Surgidas em fóruns distintos e distantes, essas propostas apontam para uma dimensão das pescarias pouco trabalhada pela geografia - a da territorialidade da atividade pesqueira e dos conflitos espaciais subjacentes a essa territorialidade.

Em uma outra dimensão, essas propostas constatam que o território da chamada pesca artesanal está sendo invadido por outras, mais recentes, formas de exploração dos recursos marinhos. Trata-se de conflitos entre formas de organização da produção pesqueira, em que as mais recentes passam a ocupar os territórios delimitados pelas mais anteriores, comprometendo a reprodução dessas últimas. Há ainda conflitos entre lógicas produtivas diferenciadas, que apontam para a sustentabilidade ou não dos recursos pesqueiros.

Vista desse ângulo, temos a pesca artesanal, compatível com a preservação dos recursos pesqueiros, sendo expropriada de seu território e do seu pescado por formas empresariais e industriais de pesca. De fato, esse é um fenômeno fortemente presente no interior da atividade pesqueira no Brasil e também em outras partes do mundo, porém a disputa por territórios e recursos pesqueiros ocorre também no interior da pequena pesca.

Alguns exemplos nesse sentido foram por nós observados no litoral norte paulista. Pescadores de cerco flutuante disputavam com pescadores de rede a rota dos cardumes; pescadores de camarão sete barbas disputavam com pescadores de cerco flutuante e de rede as mesmas áreas de pesca. Conflitos que revelam diferentes concepções de apropriação do recurso pesqueiro.
A legislação, determinando formas de captura predatórias, períodos de defeso, áreas permitidas ou vedadas para determinados tipos de pesca, cria uma territorialidade legal e acaba criando duas fontes de conflitos. A primeira com os pescadores em geral, que muitas vezes discordam das restrições impostas pela legislação e a segunda com pescadores de localidades onde a legislação não é cumprida, acarretando a invasão de áreas vedadas à pesca de arrasto pelos grandes arrastões, por exemplo.

Dois movimentos de pescadores, recentes e concretos, vêm ilustrar como o tema da territorialidade na pesca tem ganhado atualidade e visibilidade, com soluções locais derivadas dos próprios agentes envolvidos, a mercê de outras esferas de decisão.

No baixo Amazonas, nas proximidades de Santarém, comunidades ribeirinhas criaram sistemas de manejo dos lagos de várzea, que envolvem categorias de uso como lagos de subsistência e diferentes categorias de lagos abertos para a pesca comercial, restringindo 0 acesso aos lagos e exercendo um controle local sobre os recursos (M CGRATH et al., 1993).

No município de Icapuí, comunidade de Redonda, pescadores de lagosta tomaram para si a tarefa de fiscalização de um território marinho. Inoperante quando exercida pelo Ibama, a fiscalização dos pescadores tem conseguido expulsar pescadores de compressor e outras modalidades predatórias de seu território de pesca. Para julgar e punir irregularidades na pesca exercidas por membros da própria comunidade, foi ainda criada uma "justiça paralela" (FOLHA DE S. PAULO, 1996).

Embora seja necessário um maior aprofundamento com relação a essas experiências, elas nos apontam para 0 controle de um território de pesca, com formas de gestão próprias e de caráter local, ainda que as legislações determinem que as ações sobre as águas sejam de nível federal. Formalmente, 0 estabelecimento de reservas extrativistas marinhas, implantadas até 0 momento em Pirajubaé, Florianópolis (SC) e em Arraial do Cabo (RJ), representam uma nova modalidade de uso e gestão das pescarias que devem ser melhor analisadas.

\section{Novas territorialidades: desafios para 0 ordenamento das pescarias}

Questões recentes de territorialidade na pesca relacionam-se ao desenvolvimento da aquacultura e ao ordenamento para a exploração das zonas econômicas 
exclusivas (ZEE), situadas entre as 12 e 200 milhas náuticas, de escalas de abrangência diferenciadas, mas que apontam para o futuro do uso dos recursos pesqueiros e possuem uma componente geográfica bastante forte.

No caso da aquacultura, e mais especificamente da maricultura, pressupõe-se uma concessão do espaço marinho para a realização do empreendimento em qualquer escala. Ocorre que nem todas as áreas são propícias aos cultivos marinhos e aquelas que 0 são já vêm sendo disputadas por pescadores e empresas interessadas na maricultura como investimento.

Outro fato é que algumas áreas requeridas para 0 desenvolvimento da maricultura acabam resultando em áreas "tampões", impedindo 0 acesso a praias privatizadas.

A sobreposição das áreas de cultivo aos espaços de trabalho de pescadores poderá resultar em nova fonte de conflito na apropriação dos recursos pesqueiros.

Quanto ao ordenamento para a exploração das ZEE deliberado na Conferência das Nações Unidas para os Direitos do M ar, realizada em 1982, a questão que se coloca é a de quais acordos serão firmados para a exploração dos recursos pesqueiros dessa zona, uma vez que cabe ao Estado Costeiro levantar o seu potencial pesqueiro e definir cotas de exploração, que podem ou não ser divididas com outras nações. É a partir dessas deliberações que o governo brasileiro tem empreendido o Projeto REVIZZE - Recursos Vivos da Zona Econômica Exclusiva, a partir de meados dos anos 90 .

\section{Considerações finais}

Este trabalho buscou apreender algumas das proposições surgidas no interior da categoria dos pequenos produtores pesqueiros para a gestão das pescarias. Sua atualidade baseia-se nas discussões sobre manejo de recursos naturais e do papel que os chamados produtores pesqueiros artesanais possuem como agentes de um novo modelo para 0 setor pesqueiro.

Ao formatar esse modelo, deve-se levar em consideração três elementos fundamentais: o conhecimento empírico que pescadores possuem sobre a natureza, a politização de seu movimento e o território enquanto instrumento de gestão.

A análise das diferentes territorialidades presentes no universo pesqueiro - dos grupos de pescadores, da legislação, das concessões da aquicultura, do Estado Nação - revela a importância que essa categoria assume enquanto um elemento de gestão das pescarias. Torna-se, ainda, um campo de investigação rico para o estudo da Geografia.

\section{Agradecimentos}

Ao geógrafo Ricardo José Batista Nogueira e à bióloga Rosely Alvim Sanches pelo apoio na revisão e contribuições a este artigo. 
CARDOSO, E. S. (2001) Geography and fishing : contributions for a management model. Revista do Departamento de Geografia, n.14, p.79-88.

Abstract: The present paper supplies elements for the geographical study of the fisheries and for the analysis of a management model of those activities. It still analyzes the contribution of artisanal fishermen concerning a new focus for the development of the fishing activity.

Key words: Fishing ; Fishers ; Artisanal fishing ; Territory.

Recebido em 19 de junho de 2000; aceito em 31 de janeiro de 2001.

\section{Referências bibliográficas}

BERNARDES, L. M. C. (1959) Pescadores da Ponta do Cajú : aspectos da contribuição de portugueses e espanhóis para o desenvolvimento da pesca na Guanabara. Revista Brasileira de Geografia, v.20, n.2, p. 49 - 69.

BERNARDES, L. M. C. ; BERNARDES, N. (1950) A pesca no litoral do Rio de Janeiro. Revista Brasileira de Geografia, v.12, n.1, p. 1753.

BRETON, Y.; ESTRADA, E. L. (1989) Ciencias sociales y desarrollo de las pesquerías : modelos y métodos aplicados al caso de México. México, Inst. Nacional de Antropologia y Historia. $307 \mathrm{p}$.

CALVENTE, M. C. (1993) No território do azul - marinho: a busca do espaço caiçara. São Paulo, 1v. (Dissertação - M estrado) - Faculdade de Filosofia, Letras e Ciências Humanas, Universidade de São Paulo.

CAM POS, A. J. T. (1993) M ovimentos sociais de pescadores amazônicos. In: Povos das águas: realidade e perspectivas na Amazônia. Belém, Museu Paraense Emílio Goeldi. p. 231 - 242.

CARDOSO, E. S. (1996) Vitoreiros e Monteiros : ilhéus do litoral norte paulista. São Paulo, 1v. (Dissertação - Mestrado)

- Faculdade de Filosofia, Letras e Ciências Humanas, Universidade de São Paulo.

CARVALHO, M. C. V. de (1944) Santos e a geografia humana do litoral paulista. São Paulo, 1v. (Tese - Doutorado) Faculdade de Filosofia, Ciências e Letras, Universidade de São Paulo.
CUNHA, L. H. O. (1987) Entre o mar e a terra. São Paulo, 1v. (Dissertação - Mestrado) - Pontifícia Universidade Católica. DIAS NETO, J. (1996) Diagnóstico da pesca marítima no Brasil. Brasília, IBAM A. 165p.

DIEGUES, A. C. S. (1983)Pescadores, camponeses etrabalhadores do mar. São Paulo, Ática. 287 p.

DIEGUES, A. C. S. (1988) Formas de organização da produção pesqueira : alguns aspectos metodológicas. In: ENCONTRO DE CIÊNCIAS SOCIAIS E O MAR NO BRASIL, 2, São Paulo, 1988. Coletânea de Trabalhos Apresentados. São Paulo, PPCAUB/F. Ford/UICN, p. 1 - 39.

DIEGUES, A. C. S. (1992) Os pescadores artesanais e a questão ambiental . Proposta, n.53, p.31-34.

DIEGUES, A. C. S. (1995) 0 movimento social dos pescadores artesanais brasileiros. In: Povos e mares. São Paulo, NUPAUB-USP, p. 105-130.

DIEGUES, A. C. S. ; CARDOSO, E. S.; LEITÃO, W. (1992) Populações litorâneas, movimentos sociais e ecossistemas da costa brasileira. São Paulo, CEMAR. 234p.

FOLHA DE S. PAULO (1996) Pescadores criam justiça paralela no CE. São Paulo.

FÓRUM INTERNACIONAL de ONGs e Movimentos Sociais, Fórum Brasileiro de ONGs e M ovimentos Sociais Para 0 Meio Ambiente (1992) Tratados das ONGs. Rio de Janeiro. $264 p$.

FRANÇA, A. (1954) A ilha de São Sebastião: estudo de geografia humana. São Paulo, FFCL - USP, 195p. (Boletim, 178). 
FURTADO, L. G. (1993) "Reservas Pesqueiras", uma alternativa de subsistência e de preservação ambiental : reflexões a partir de uma proposta de pescadores do médio Amazonas. In: Povos das águas: realidade e perspectivas na Amazônia. Belém, M useu Paraense Emílio Goeldi. p. 243 - 276.

IBGE (1971) Anuário Estatístico do Brasil. Rio de Janeiro, FIBGE, p.134-142.

IBGE (1990) Estatística da Pesca 1989. Rio de Janeiro, FIBGE, v.10, n.1,69p.

IBGE (1991) Estatística da Pesca 1989. Rio de Janeiro, FIBGE, v.10, n.2, 68p.

JORNAL DA PESCA (1971) Desenvolvimento da indústria pesqueira no Brasil. Santos.

LAGO, P. F. A. (1961) Contribuição geográfica ao estudo da pesca no litoral de Santa Catarina. Revista Brasileira de Geografia, v. 23, n.1, p. 121 - 215.

LOUREIRO, V. R.(1985) Os parceiros do mar. Belém, CNPQ/M useu Emílio Goeldi. 227 p.

M ALDONADO , S. C. (1996) Pescadores do mar. São Paulo, Ática. 77p.

MALDONADO , S. C. (1988) No mar : conhecimento e produção. In: ENCONTRO DE CIÊNCIAS SOCIAIS E O MAR NO BRASIL, 2, São Paulo, 1988. Coletânea de Trabalhos Apresentados. São Paulo,PPCAUB/F. Ford/UICN. p. 259 - 265.

MALDONADO, S. C. (1993) M estres e ares : espaço e indivisão na pesca marítima. São Paulo, Annablume. 195 p.

M cGRATH, D.; CASTRO, F.; FUTEM M A, C. R.; AM ARAL, B. D..; CALABRIA, J. A. (1993) Manejo comunitário da pesca nos lagos de várzea do Baixo Amazonas. In: Povos das águas: realidade e perspectivas na Amazônia. Belém, Museu Paraense Emílio Goeldi. p. 213 - 230.

MARQUES, J. G. W. (1995) Pescando pescadores : etnoecologia abrangente no baixo São Francisco alagoano.

São Paulo/M aceió, NUPAUB-USP. 304 p.

M ARTINS, J. S. (1986) Pequena produção agrícola : antimito da produção capitalista no campo. In: Reforma agrária e os limites da democracia na "Nova República". São Paulo, Hucitec. p. 113 - 152.

M ARTINS, J. S. (1989) Dilemas sobre as classes subalternas na idade da razão. In: Caminhada no chão da noite. São Paulo, Hucitec. p. 97 - 147.

MELLO, A. F. (1985) A pesca sob o capital. Belém, UFPA. 296 p. M ONAPE (1991) Pescando e lutando. São Luís, M ovimento Nacional de Pescadores, 12p.
M ORAES, A. C. R. (1984) Território. Orientação, n.5. p. 91.

MUSSOLINI, G. (1980) Cultura caiçara. In: Ensaios deantropologia indígena e caiçara. Rio de Janeiro, Paz e Terra. p. 219 - 289.

NOFFS P. S. (1988) Os caiçaras de Toque - Toque Pequeno: um estudo de mudança espacial. São Paulo, 1v. (Dissertação - Mestrado) - Faculdade de Filosofia Letras e Ciências Humanas, Universidade de São Paulo.

PAIVA, M. P. (coord.) (s/d) Levantamento do estado da arte da pesquisa dos recursos vivos marinhos do Brasil. Brasília, SMA/M M A/Prog. REVIZZE, Rel. Interno, 241p.

PROJ ETO CULTURAL SÃO SEBASTIÃO TEM ALM A (1990) Carta do caiçara. São Sebastião.

PROJ ETO CULTURAL SÃO SEBASTIÃO TEM ALMA (1993) Carta do pequeno encontro dos povos do mar. São Sebastião.

PROJ ETO CULTURAL SÃO SEBASTIÃO TEM ALM A; PROGRAM A DE PESQUISA E CONSERVAÇÃO DE ÁREAS ÚM IDAS NO BRASIL (1990) Carta do ilhéu. São Sebastião.

PROJ ETO CULTURAL SÃO SEBASTIÃO TEM ALM A; CENTRO DE CULTURAS M ARÍTIMAS (1992) Carta dos povos do mar. São Sebastião.

PROJ ETO CULTURAL SÃO SEBASTIÃO TEM ALMA; NUPAUBUSP; FUNDO SOCIAL DE SOLIDARIEDADE DE ILHABELA (1994) Carta dos povos do mar e da mata atlântica. São Sebastião.

SADER, E. (1995). Quando novos personagens entraram em cena. 2. ed. Rio de Janeiro, Paz e Terra, $329 \mathrm{p}$.

SANTOS, M. (1996) A natureza do espaço. São Paulo, Hucitec. $308 \mathrm{p}$.

SILVA, L. G. S. (1988) Os pescadores na história do Brasil. Recife, CPP/Vozes. $222 \mathrm{p}$.

SILVA, L. G. S. (1989) M ovimento social de pescadores no norte e nordeste brasileiros : tradição e mudança (1966 - 1988).In: ENCONTRO DE CIÊNCIAS SOCIAIS E O MAR, 3, São Paulo, 1989. Coletânea de Trabalhos Apresentados, São Paulo, PPCAUB/F.Ford/UICN, p. 141 - 156.

SILVA, L. G. S. (1991) Pescadores, militares e burgueses: legislação pesqueira e cultura marítima no Brasil (1840 - 1930). Recife, 1v. (Dissertação - M estrado) - Centro de Filosofia e Ciências Humanas, Universidade Federal de Pernambuco.

SILVA, L. G. S. (1998) História e meio ambiente: a pequena pesca marítima no Brasil. Revista de Sociologia e Política, n. 10/11, p. $219-231$.

SILVA, P. C. M. (1972) 0 problema da pesca no Brasil. In: Estudos do Mar Brasileiro. Rio de Janeiro, Renes. p. 7 - 44. 